\title{
Can students learn from PhET Sims at home, alone?
}

\author{
Wendy K. Adams ${ }^{1,2}$, Zachary Armstrong ${ }^{1,2,3}$ and Cynthia Galovich ${ }^{1}$ \\ ${ }^{1}$ University of Northern Colorado, Department of Physics and Astronomy, \\ ${ }^{2}$ University of Northern Colorado, Science Education Programs, $50120^{\text {th }}$ Street, Greeley, Colorado 80639 \\ ${ }^{3}$ Greeley West High School, $240135^{\text {th }}$ Avenue, Greeley, Colorado, 80634
}

\begin{abstract}
Most previous work on student learning with PhET Sims focuses on classroom environments where students work in groups, with scaffolding from both worksheets and instructors. By contrast, we present a study that demonstrates students can learn from PhET Sims when working independently, both in class and at home, when using appropriately scaffolded worksheets. Here we explore the space of when and how students can learn individually from PhET Sims.
\end{abstract}

PACS: 01.40.-d, 01.40.G-, 01.50.H-, 01.50.Lc

\section{INTRODUCTION}

PhET Interactive Simulations (sims) have been shown to be effective learning tools in many contexts [1] and are now broadly accepted by the Physics Education Research Community as effective educational tools. PhET Sims are unique in that they provide the appropriate structure through balanced challenges that allow students to engage in exploration as a scientist would. However, research has demonstrated that sim effectiveness depends on how they are used with students. Our experience from years of student interviews, classroom observations and evaluation of various types of in class activities, has found many types of instruction fail to actively engage students with the sims. Extensive student interviews [2] have shown that sims are educationally effective only if the student's interaction with the sim is directed by the student's own questioning. Therefore, PhET Sims are not automatically effective in every context.

Here we will explore a context that other studies of PhET Sim effectiveness, to our knowledge, have not - individual student use. To better understand the space of when and how students can learn individually from PhET Sims we studied four different types of interactions: 1 . In class wrapped with Driving Questions; 2. At home wrapped with Driving Questions; 3. At home via a Mastering Physics Tutorial [3]; and 4 . At home without wrapping.

\section{A. PhET Sims are Unique - they do not require peer interaction to facilitate student engagement}

Research on learning shows that to develop expert problem solving and understanding in science, students must actively build that understanding [4]. This is done through effortful practice, which requires focus and motivation, and feedback on the student's thinking. Active-learning instructional methods "...aim to generate, through interactions with peers and instructors, understandings that eventually match those of physicists." [5] PhET Sims facilitate those same processes in ways that other teaching methods cannot.

Review of prior research reveals that all studies of PhET Sims, outside of individual student interviews, used activelearning instructional methods. Lecture examples utilized Peer Instruction [6,7] and/or Interactive Lecture Demonstrations [8], and both in class activities and labs utilized carefully crafted guided inquiry activities $[9,10]$. All of these studies involve interactions between peers as they explore the sims in small groups.

In this study we demonstrate that PhET Sims wrapped with an appropriately scaffolded worksheet can successfully engage individual students in exploration of the material and produce healthy learning gains without peer interaction. In addition we show that these same activities were successful in generating equivalent levels of learning when used as homework, providing evidence that students are also engaging in exploration with the sims at home, on their own.

\section{B. Not all types of guidance are effective}

Adams and colleagues [11] published one of two studies that evaluate different types of instruction with PhET Sims demonstrating a range of effectiveness depending on the type of instruction used. Four different types of guidance were evaluated via individual student interviews and only two of those four were successful at promoting engaged exploration with the sims - no guidance and minimal guidance via Driving Questions (eg. Can you make a light bulb light with a magnet?). However, the value of this study is limited to the context of student interactions in an interview setting.

A more recent study by Chamberlain et al. [12] evaluated three different levels of guidance - heavy, moderate and light - in small groups during recitation. They found that students explored more and attended to their sim interactions more in the light guidance condition and least in the heavy guidance condition. 
To further extend this work we have collected evidence in both college and high school classrooms using different levels of guidance for individual use both in class and at home. We have had success using activities with Driving Question type guidance, which is most similar to Chamberlain et al.'s moderate guidance. After multiple trials with PhET Sim activities, so far we have been unable to create effective activities with either a heavy guidance condition or light/no guidance.

\section{EFFECTIVE INDIVIDUAL ACTIVITIES}

To determine if PhET Sims wrapped with Driving Questions can be engaging and effective learning tools, when used individually without peer interaction, we carefully studied PhET Sim use in three sections of a high school physics classroom. One period used them in class while we observed, and the other periods used them at home. Data is presented for three different activities which utilize five different PhET Sims in total.

First we carefully evaluated the in class use through observations and pre/post measures of student learning. Since it is impossible to observe student interactions with sims at a student's home, we will use student learning as a proxy for engagement. Extensive interview studies with PhET Sims have found that students do not learn from the sims unless they engage in exploration via their own questioning [2]. If these PhET Sim activities are effective at engaging these students individually during class, and we see equivalent learning gains when used at home, we have evidence that the students are indeed engaging in exploration outside of class on their own.

\section{A. Participants and Design}

This study was conducted using three sections of a second semester introductory high school physics course, with 77 participants. The participants were in grades 10 through 12 and between 15 and 18 years of age. About $60 \%$ are male, and are similar ethnically and socioeconomically to the school as a whole: $52 \%$ Hispanic, $41 \%$ Caucasian and $48 \%$ eligible for free and reduced lunch.

Participants were divided into two groups: "sim as homework" and "sim in class". Sections were randomly assigned to a group, with two of the sections placed in the "sim as homework" group. Each section had either "sim in class" or "sim as homework" for the duration of the study so that the sim activities would appear to be part of normal instruction. Evidence for the equivalence of the groups is found in a comparison of first semester grades which represents the approximate academic preparation of the students, tempered by their motivation. Additional evidence for group equivalency can be seen in the pre-test scores in Table 1.

Each sim activity was presented and evaluated using the same cycle. On day one, the students were given a pre-test and the next day's activities were explained, making students aware that computer access was needed. On day two, the students received two assignments: the sim activity and an unrelated practice/review assignment, such as an assignment on conversions. The students individually completed one assignment in class and received the other at the end of class to complete as homework. On day three, the students submitted their homework and took the post-test. There was no instruction other than the individual PhET Sim activity and unrelated review activity between the pre and post tests. Students were not told if the activities or pre/post tests would be graded.

\section{B. Data and Results}

Each pre/post-test had three or four content specific questions that were conceptually based and did not specifically reference the sims. For example, from the states of matter pre/post-test, one of the questions asks, "When you rub your hands together, why do they get hot?" Pre/posttests were graded using a rubric and points were assigned using a 0 to 3 point scale (see [13] for specific rubrics and pre/post tests). The rubrics were designed to allow students to earn points for partial understanding of a topic and multiple versions of correct answers. The tests were scored by ZA and by another instructor at the same high school to establish inter-rater reliability; with an agreement of $96 \%$. Any discrepancies were discussed and resolved. Only students who completed both the pre and the post-test were retained for each sim cycle.

The PhET Sim activities and unrelated assignments were graded for completion, to satisfy the human subjects requirements, and the grade was applied to their course grade. Completion was assessed using a 0 to 3 point scale. Activities/assignments were given a score of 3 if they were $90 \%$ to $100 \%$ complete; 2 if they were $60 \%$ to $89 \%$ complete; 1 if $30 \%$ to $59 \%$ complete; and, 0 was for $29 \%$ or less complete.

As part of the post test, students were asked how much time they spent on the PhET Sim activity. In order to evaluate only those students who used the sim, we removed students who chose the option "I didn't try or forgot to do the assignment". In addition, only students who completed at least $30 \%$ of the activity were retained for each sim cycle. As expected, a higher fraction of the in class students completed the activities compared to the homework condition, $92 \%$ in class students completed the sim activity while only $57 \%$ of students completed the sim homework. This is somewhat disappointing and it is also a typical homework completion rate for this high school.

Table I shows that students who completed $30 \%$ or more of an activity had healthy learning gains in both the in class and at home conditions. The Faraday induction activity was particularly effective with an effect size over 2 in each condition. We discuss our evaluation of the differences in these three activities in section $\mathrm{D}$. below. 
TABLE I. Pre/post: Individual use in and out of class

\begin{tabular}{c|c|c|c|c}
\hline & Pre & Post & $\langle\mathrm{g}\rangle$ & $\boldsymbol{d}$ \\
\hline Static electricity & & & & \\
\hline In class & $60.6(5.9)$ & $76.1(3.6)$ & 0.39 & 0.70 \\
\hline At home & $62.1(4.4)$ & $77.0(2.4)$ & 0.39 & 0.81 \\
\hline Faraday induction & & & & \\
\hline In class & $3.2(1.3)$ & $60.9(5.6)$ & 0.60 & 2.8 \\
\hline At home & $2.8(1.6)$ & $56.9(6.3)$ & 0.56 & 2.4 \\
\hline Nature of matter & & & & \\
\hline In class & $56.1(4.0)$ & $70.6(3.7)$ & 0.33 & 0.89 \\
\hline At home & $48.5(3.8)$ & $68.2(3.9)$ & 0.38 & 1.1 \\
\hline 0
\end{tabular}

()$=$ Standard Error, $\langle\mathrm{g}\rangle=$ normalized learning gain, $d=$ effect size - Cohen's $d$

\section{Classroom Observations}

During in class use, students were instructed to complete the sim in class on their own computer. They were neither encouraged nor discouraged to talk. Students predominantly worked on their own; however, when they ran into a difficulty or found something entertaining they shared it with their nearest neighbor. For example, when using Balloons and Static Electricity, the final question is rather challenging, asking, "Can you get the two balloons to be attracted to each other?" Particularly exciting moments that were shared included extremes demonstrated by the sims including: Blowing the lid off of the container in States of Matter; a very bright light bulb or quickly spinning magnet in Faraday's Electromagnetic Lab; or, an excessive amount of electrons or large spark in John Travoltage.

The instructor observed and remained disengaged, not helping the students during the in class activities in order to create as similar of an environment as possible to the homework condition. These observations revealed students on task and engaged with their sims. The level of engagement exceeded that of a typical class day. This observation is supported by the completion rate of the sim activities compared to the unrelated review activities, $92 \%$ and $78 \%$ respectively.

\section{Activity Design}

These activities were designed using principles of effective sim use [13] and have been used in the college classroom as well. Each activity begins with a prompt instructing the student to "investigate the sim and use it to answer the following questions." The questions that follow are about physical phenomena described in the sim. For each sim between two and eight Driving Questions follow this prompt. For example, when using Faraday's Electromagnetic Lab, one of the questions asks, "How does using AC current affect a compass needle?" or when using States of Matter, the student is asked, "Can you get the molecules to stop wiggling?" The students are never instructed to use a particular button or slider, it is up the student's discretion to determine how they will manipulate their sim to help them answer the question. These types of questions encourage students to investigate the sim and to build their own understanding of phenomena.

When choosing questions, we first determined our learning objectives and simply asked questions that directly addressed each objective. We were also cognizant of common student pre-conceptions when developing our objectives. For example, trying to show students that when something gains a static charge, protons are not transferred and that uncharged objects contain an equal number of both protons and electrons. To address this, students are instructed to "charge an object positive and explain how it became positively charged."

The data demonstrate that not all of these PhET Sim activities, as measured by their associated pre/post test, were created equal. The Faraday induction activity had a substantially larger learning gain and effect size. This topic was new to these students leaving a tremendous amount of room for growth. We have also found that this sim, Faraday's Electromagnetic Lab, is one of the better PhET Sims. Its structure provides more scaffolding than the others used in this study, building the concept of induction a piece at a time. WA conducted many student interviews as part of the development of this sim and found that it was particularly effective at building the complicated concept of induction. It is also clear that the high school students in this study were aware that they did not understand this topic before the activity, which could have affected how seriously they engaged in the activity, also consistent with student interview data.

\section{INEFFECTIVE INDIVIDUAL ACTIVITIES}

In this section we will describe two different types of homework guidance with PhET Sims that have not produced strong learning gains. In both cases, we expected these assignments to be effective and have had many conversations with other instructors who agree that common sense tells us that these two types of homework should "work". Both are drawn from a college level introductory algebra based course. In each case, the strategy was used during three different terms $(n=78, n=103, n=28)$ with similar results each term. Specific data is presented from the larger course, $\mathrm{n}=103$, when $\mathrm{i}>$ clickers were used. The first is a Mastering Physics problem using the Projectile Motion sim and the second is a commonly suggested strategy of showing students a particular sim in class and recommending that they use it at home to help them understand the material.

\section{A. Heavy guidance at home}

Mastering Physics offers a problem called "PhET Tutorial: Projectile Motion" which is text heavy and includes involved problems requiring a substantial cognitive load. It includes 13 parts, A-M, designed to walk a student through 
the important concepts of projectile motion by encouraging students to try out a particular scenario through the use of the sim. It is consistent with the heavy guidance condition in [12] and contains explicit instruction about sim settings. Parts $\mathrm{C}$ $\mathrm{M}$ are multiple choice set to allow multiple attempts with a penalty for incorrect answers.

This Tutorial was given as part of a pre-reading quiz, $67 \%$ of students completed the Tutorial with an average score of $84 \%$. During the following class period, part $\mathrm{F}$ was asked as a clicker question, Fig $1.86 \%$ of enrolled students answered the question, with $31 \%$ answering correctly before discussion and 30\% answering correctly after discussion. Interestingly, $62 \%$ choose option $\mathrm{C}$.

Based on the figure, for which trajectory was the ball in the air for the greatest amount of time?

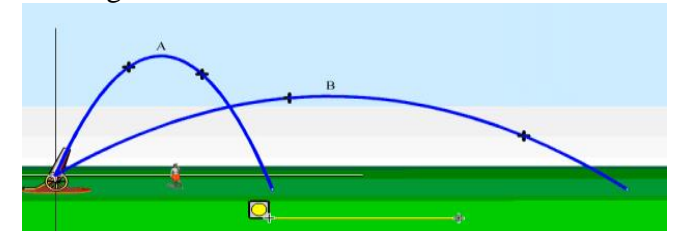

A. Trajectory A, B. Trajectory B, C. The balls were in the air for the same amount of time, d. Impossible to tell based solely on the picture.

FIG 1. Part F of PhET Tutorial: Projectile Motion.

The sim was then demonstrated in class followed by group discussions and then a whole class discussion. On the exam the following week $80 \%$ answered correctly.

This data provides evidence that students completed the Tutorial but did not learn the concepts they explored. However, consistent with prior work, using the sim as an Interactive Lecture Demonstration resulted in substantial gains.

\section{B. Light/No Guidance at Home}

To study the light/no guidance with individual use condition, PhET Sims were assigned by putting linked screen

[1] see the research section of the PhET website http://phet.colorado.edu/new/research/index.php

[2] W. K. Adams, S. Reid, R. LeMaster, S. B. McKagan, K. K. Perkins, M. Dubson and C. E. Wieman. J. Interactive Learning Res., 19. (2008).

[3] E.S. Morote and D. E. Pritchard, Am. J. Phys. 77 (2009)

[4] J. Bransford, A. Brown, R. Cocking, Eds. How People Learn: Brain, Mind, Experience, and School (National Academy Press, Washington, DC, 2000).

[5] D. E. Meltzer \& R. K. Thornton, Am. J. Phys., 80, (2012), p 479

[6] K. Perkins, W. Adams, M. Dubson, N. Finkelstein, S. Reid, C. Wieman, \& R. LeMaster, Phys. Teach., 44, (2005).

[7] C. H. Crouch \& E. Mazur, Am. J. Phys. 69 (2001). shots into the class slides (posted online before class and remain available) with the instruction that, "this sim shows " $\mathrm{x}$ " concept and by exploring it, you will be better prepared for the homework, quiz and exam. It is strongly recommended that you try it at home." The instructor got the sense that during the following classes, most students had not engaged with the $\operatorname{sim}(\mathrm{s})$. To measure this more precisely, on two occasions, students were polled within a week of the assignment, $0-5 \%$ report having worked through the sim, $5 \%$ looked at it, 29\% thought about it but did not open it, $57 \%$ forgot to look and $5 \%$ never intended to look.

We believe the reason for these poor results is that this level of guidance does not provide adequate motivation for students to engage at home on their own time. It also does not have a structure that allows for a straightforward and fair mechanism for grading this type of "assignment" in an effort to externally motivate students to explore the sim.

\section{CONCLUSIONS}

When exploring the space of individual student use of PhET Sims, we found that both in class and at home, students will engage in exploring PhET Sims via their own questioning. However, this type of interaction only occurred with Driving Question/moderate guidance type scaffolding which provided motivation and initial questions for students to investigate.

We measured learning gains on par with interactive engagement techniques, which require students to interact with their peers as they work through the material. Here students were working alone with PhET Sims, which allowed a similar type of inquiry supported by sim features such as concrete connections to the real world, and a high level of interactivity with real-time, dynamic feedback from the sim.

[8] D. R. Sokoloff \& R. K. Thornton, Phys Teach, 35, (1997).

[9] N.D. Finkelstein, W. K. Adams, C. J. Keller, P. B. Kohl, K. K Perkins, N. S. Podolefsky, S. Reid, R. LeMaster., Phys. Rev. ST Phys. Educ. Res., 1 (2005).

[10] K. Perkins, E. Moore, N. Podolefsky, K. Lancaster and C. Denison, AIP Conf. Proc. (2012).

[11]W. K. Adams, A. Paulson and C. E. Wieman, AIP Conf. Proc., 1064, 1 (2008).

[12] J. Chamberlain, K. Lancaster, R. Parson and K. K. Perkins, Chem. Educ. Res. \& Practice, 15.

[13] Activities, pre/post tests and rubrics can be found at http://www.unco.edu/nhs/physics/faculty/adams/Resear ch/Armstrong Supplementary.pdf

[14] Tips for Using PhET can be found here: http://phet.colorado.edu/en/teaching-

resources/tipsForUsingPhet 